\title{
A utilização da casca da banana como substituição de parte do cimento na produção de tijolos ecológicos: a busca por alternativas sustentáveis
}

\section{The use of banana peel as a replacement of part of the cement in the production of ecological bricks: the search for sustainable alternatives}

\author{
Diego Silva ${ }^{1}$ \\ Mateus Bravo de Aguiar ${ }^{2}$
}

\begin{abstract}
Resumo
Esta pesquisa consiste no estudo das propriedades do tijolo confeccionado a partir do pó da casca de banana, suas características quanto à resistência e sua incorporação como alternativa sustentável na construção civil. Foi utilizado solo tipo argila-arenosa e o cimento CPIIZ-32 provenientes das imediações do laboratório de ensaios e campo da Pontifícia Universidade Católica de Minas Gerais (PUC Minas) e as cascas de bananas coletadas do restaurante popular do Barreiro em Belo Horizonte para moldagem dos corpos de prova. Os métodos utilizados para avaliar o comportamento destes tijolos foram feitos a partir de ensaios de compressão simples e absorção de água. Para a determinação da mistura de solo-cimento foram estudados dois teores de resíduos da casca da banana ( $2 \%$ e $4 \%$ ), sendo confeccionados 18 corposde-prova ao todo, 6 para cada formulação, incluindo a de solo cimento, nas idades de 7 e 14 dias. Os resultados dos ensaios tecnológicos foram comparados de acordo com as normas da ABNT - Associação Brasileira de Normas Técnicas.

Palavras-chave: Construção civil. Casca de banana. Sustentabilidade.
\end{abstract}

\begin{abstract}
This research is the study of the brick properties made from banana peel powder, its characteristics as resistance and its incorporation as a sustainable alternative in construction. It was used soil type claysandy and CPIIZ-32 cement from the vicinity surroundings and field at the Catholic University of Minas Gerais (PUC Minas) and the peels of bananas was collected in the popular Barreiro restaurant in Belo Horizonte for molding of the specimens. The methods used to evaluate the performance of these bricks were made from a simple compression test and water absorption. For determining the soil-cement mixture were studied two residues of banana peel ( $2 \%$ and $4 \%$ ) and made up 18 bodies of the test piece as a whole, 6 for each formulation, including ground cement in ages of 7 and 14 days. The results of technological tests were compared according to the norms of ABNT Brazilian Association of Technical Standards.
\end{abstract}

Keywords: Building. Banana peel. Sustainability.

Artigo recebido em 30 de Junho de 2016 e aprovado em 18 de Outubro de 2017.

${ }^{1}$ Discente do curso de Engenharia Civil - PUC Minas/Barreiro. E-mail: dieggo.177@ hotmail.com

${ }^{2}$ Discente do curso de Engenharia Civil - PUC Minas/Barreiro. E-mail: mateus.aguiar@sga.pucminas.br 


\section{Introdução}

A construção civil tem crescido rapidamente nos últimos anos, sendo uma das atividades que mais deteriora os ecossistemas, polui o meio ambiente e gera resíduos. Jhon apud Ribeiro Filho et al. (2006) realizou pesquisas na área de construção civil e constatou que as obras de infraestrutura são responsáveis por $75 \%$ do consumo dos recursos naturais do planeta. Com esse crescimento desenfreado e sem a preocupação em preservar o meio ambiente e seus recursos naturais, surgiu a necessidade de se implantar o desenvolvimento sustentável na construção civil.

O termo desenvolvimento sustentável surgiu em 1983, por ocasião da Comissão Mundial sobre Meio Ambiente e Desenvolvimento, criada pela ONU. Presidida pela então primeira-ministra da Noruega, Gro Harlem Brudtland, essa comissão propôs que o desenvolvimento econômico fosse integrado à questão ambiental, estabelecendo-se, assim, o conceito de "desenvolvimento sustentável".

Os trabalhos foram concluídos em 1987, com a apresentação de um diagnóstico dos problemas globais ambientais, conhecido como Relatório Brundtland (1987). Nesse relatório era proposto o desenvolvimento sustentável definido como "aquele que atente às necessidades do presente sem comprometer a capacidade de as gerações futuras atenderem as suas necessidades". Na Eco-92 (Rio-92), essa nova forma de desenvolvimento foi amplamente difundida e aceita e o termo ganhou força. Nessa reunião, foi assinada a Agenda 21, que pode ser definida como um instrumento de planejamento para a construção de sociedades sustentáveis em diferentes bases geográficas, conciliando métodos de proteção ambiental, justiça social e eficiência econômica.

Diante deste contexto, surgem novos materiais sustentáveis que são de grande importância para a construção civil, como, por exemplo, a formação de tijolos ecológicos visando à reutilização de resíduos. Dentre os resíduos se destacam as cinzas minerais oriundas de diferentes atividades agroindustriais, que apresentam altas porcentagens de sílica e de outros óxidos, podendo ser então utilizadas como pozolanas. A propriedade da pozolana é a sua capacidade de reagir com o hidróxido de cálcio liberado durante o processo de hidratação do cimento, formando compostos estáveis de poder aglomerante, tais como os silicatos e aluminatos de cálcio hidratados. (OLIVEIRA, 2004). 
Baseado em pesquisas e métodos já utilizados e comprovados, é possível a produção de tijolos oriundos das cinzas do bagaço da cana-de-açúcar, pois essa cinza tem potencial para ser utilizada como adição mineral, substituindo parte do cimento em argamassas e concretos. (CORDEIRO, 2008). Com isso, essa pesquisa teve como possibilidade a redução do uso do cimento, material produzido da fusão do calcário e argila, e amplamente utilizado na construção civil.

Com foco nesses paradigmas sustentáveis, algumas construtoras buscam soluções verdes para construir minimizando os impactos sobre o meio ambiente, reduzir a emissão de gases poluentes na atmosfera e diminuir os resíduos gerados na construção, dessa forma buscando o desenvolvimento sustentável e o bem-estar social.

Estudos realizados por Bernabé (2014) mostram que a casca de banana possui a sílica em sua composição, um composto químico presente no cimento e extremamente importante na fabricação do tijolo, podendo auxiliar na produção de um material ambientalmente adequado e tecnicamente viável. Partindo dessa premissa, o objetivo desse trabalho foi avaliar se a sílica contida na casca da banana possui propriedades suficientes para substituir parte do cimento na fabricação do tijolo.

\section{Materiais e métodos}

Os ensaios desenvolvidos nesta pesquisa foram realizados no laboratório de ensaio e campo da Pontifícia Universidade Católica de Minas Gerais (PUC Minas), no Coração Eucarístico. Nesse local, obteve-se a maioria dos materiais necessários para a execução dos corpos de prova (exceto as cascas de banana), que foram moldados e prensados na fábrica ECOBAUER de tijolos ecológicos, em Nova Lima/MG.

\subsection{Matéria prima}

As cascas de banana foram a principal matéria-prima estudada, sendo coletadas aproximadamente 600 cascas de banana com diferentes tamanhos e tipos (caturra, prata e maçã) no restaurante popular do bairro Barreiro em Belo Horizonte. As cascas foram colocadas em telhados e em uma cobertura de um prédio, para assim secarem por efeito dos raios solares (Figura 1), durante um período de 20 dias. 


\section{Figura 1 - Secagem das cascas de banana pelo sol}

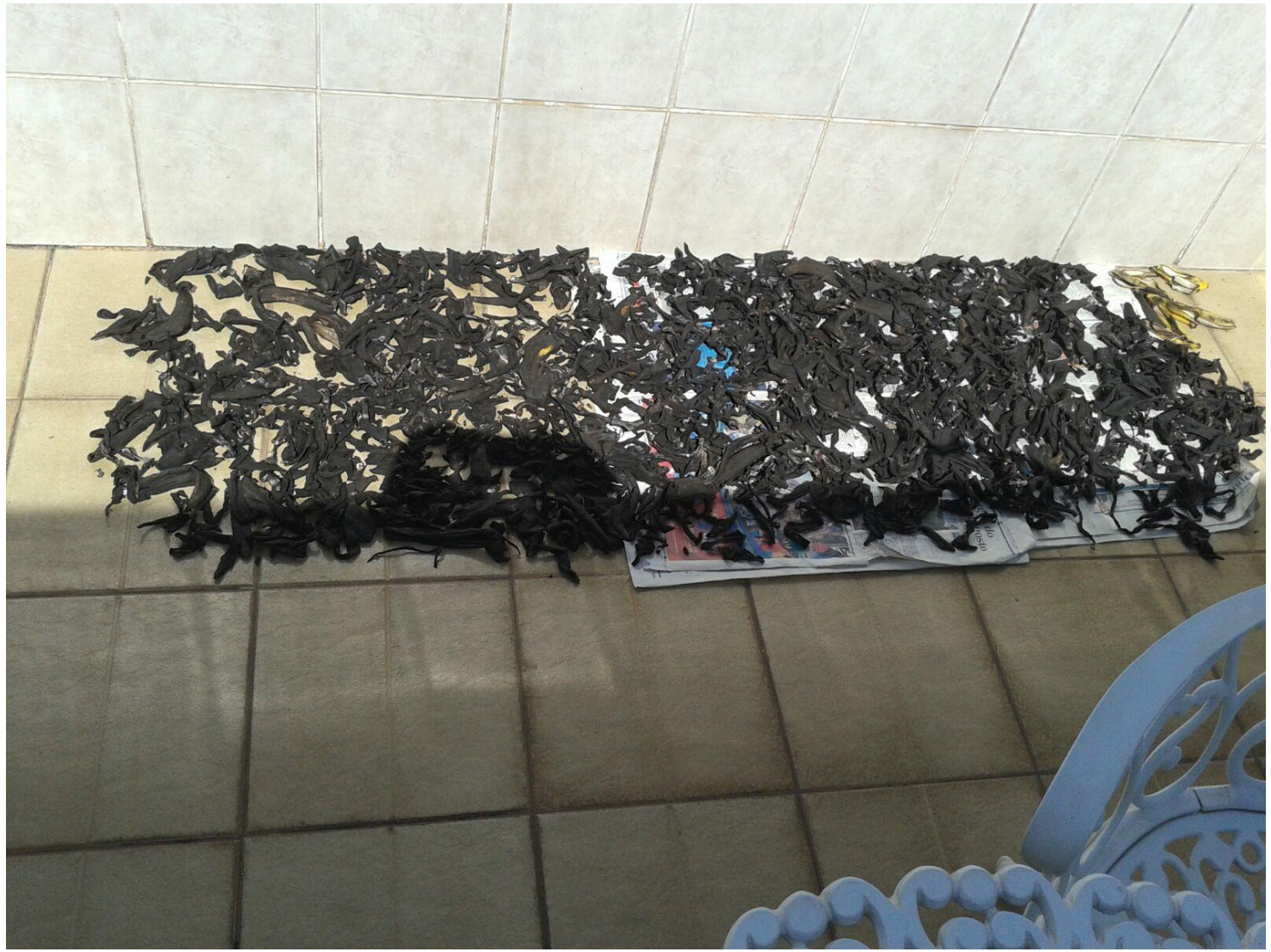

Fonte: Autoria própria, 2015.

O solo utilizado no trabalho foi coletado nas imediações do laboratório de campo da Engenharia Civil, na PUC Minas, Coração Eucarístico. Foram $30 \mathrm{Kg}$ de solo coletado com o caráter argila-arenosa. Na fabricação dos corpos de prova (CP's) utilizou-se o cimento CPZII-32, cedido pelo laboratório de Engenharia Civil da PUC Minas.

\subsection{Moldagem do corpo de prova}

Após a sua secagem, as cascas de banana foram trituradas em um liquidificador da marca Walita, até virarem um pó bem fino com granulométrica de aproximadamente $0,04 \mathrm{~mm}$, passante na peneira 4.8 .

Constituintes do corpo de prova, o solo, o cimento e o pó das cascas de banana, foram pesados em uma balança com precisão de $5 \mathrm{~g}$ da marca Marte (Figura 2) no laboratório de química da PUC Minas do Barreiro. No período da pesagem foram medidas e separadas cada concentração suficiente para a moldagem de cada corpo de prova, com as proporções de cimento, solo e casca. 
Tabela1- Proporções de matéria prima utilizada

\begin{tabular}{lccc}
\hline Proporções & Cimento(g) & Solo(g) & Casca de Banana(g) \\
\hline & & & \\
1 Proporção & 600 & 2400 & 60 \\
2 Proporção & 540 & 2400 & 120 \\
3 Proporção & 480 & 2400 & \\
& & & \\
\hline \hline
\end{tabular}

Fonte: Autoria própria, 2015.

Cada bloco de tijolo pesou $3 \mathrm{~kg}$, sendo que as proporções foram separadas de acordo com a tabela 1 .

Figura 2 - Pesagem das Proporções

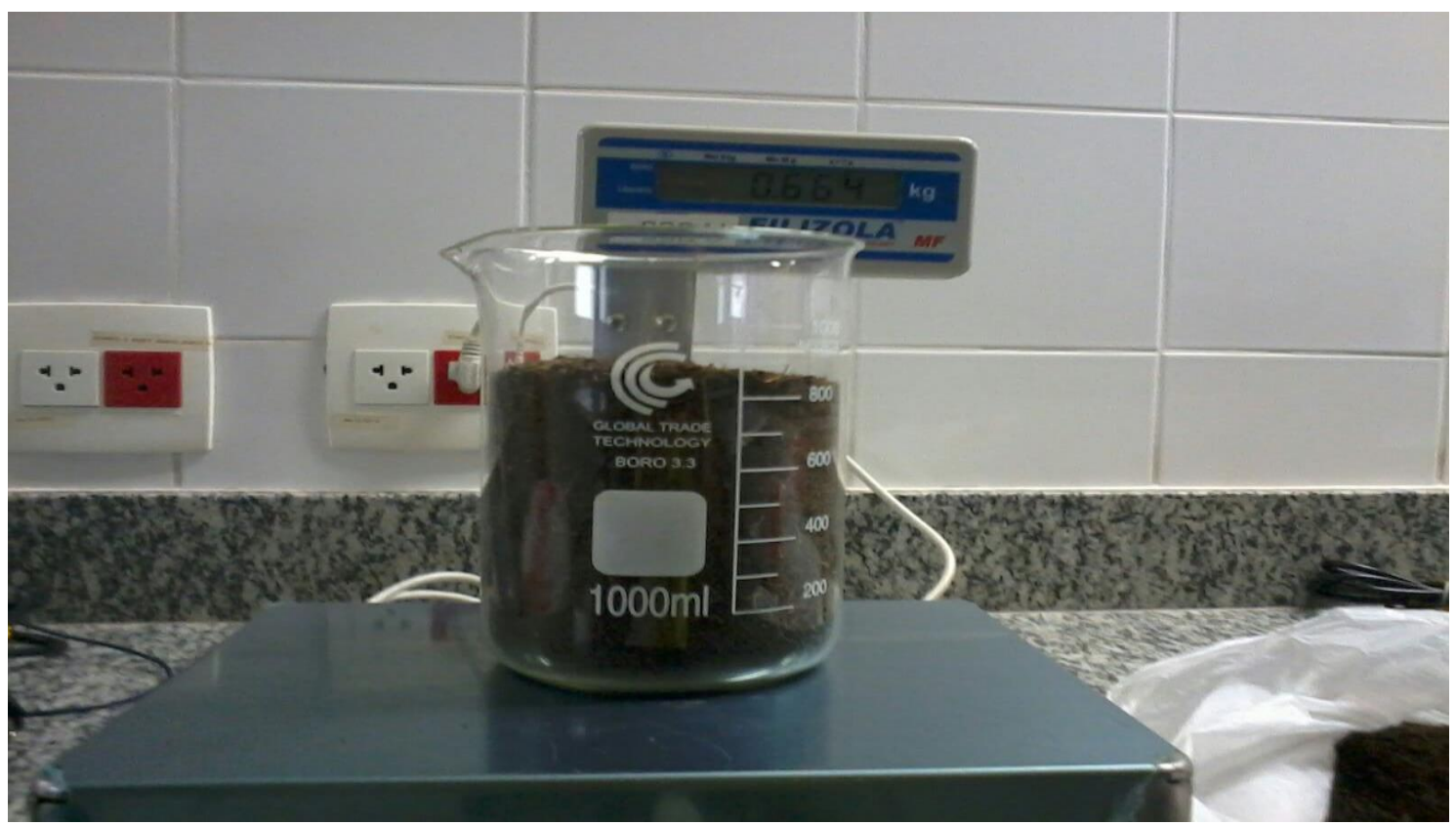

Fonte: Autoria própria, 2015.

Após as devidas proporções serem separadas, foram levadas para a fábrica, onde todos os constituintes foram misturados com água (figura 3), até se tornarem uma mistura homogênea. A mistura foi colocada na máquina de fazer tijolos, conhecida também como prensa hidráulica (Figura 4). Após prensado, o material obteve a forma de um tijolo. 
Figura 3 - Mistura dos materiais.

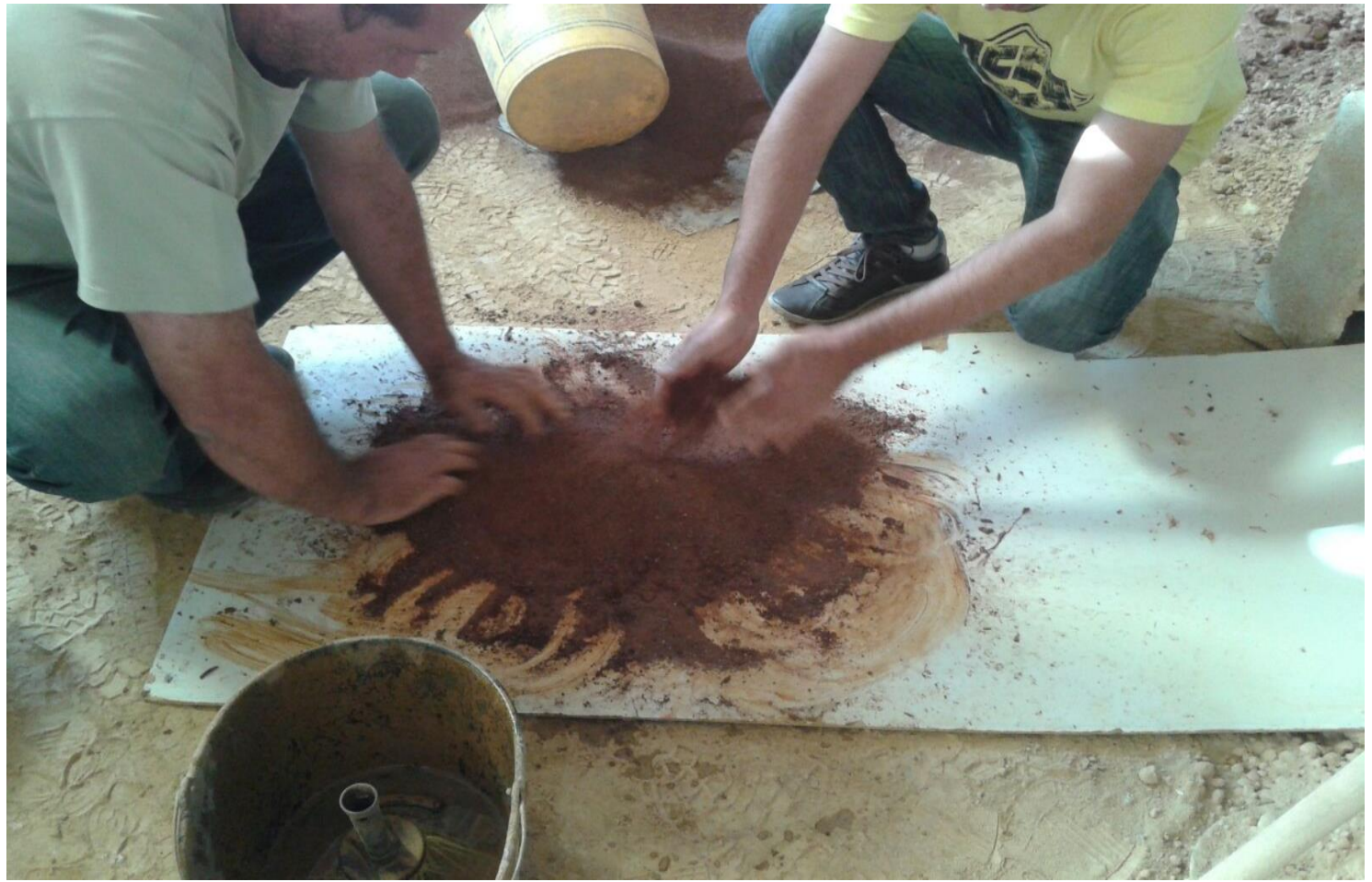

Fonte: Autoria própria, 2015.

A mistura foi feita manualmente com a ajuda dos trabalhadores da fábrica. Adicionou-se pouca quantidade de água na mistura (aproximadamente $100 \mathrm{ml}$ ) suficiente apenas para umedecê-la. 
Figura 4 - Prensagem dos corpos de prova

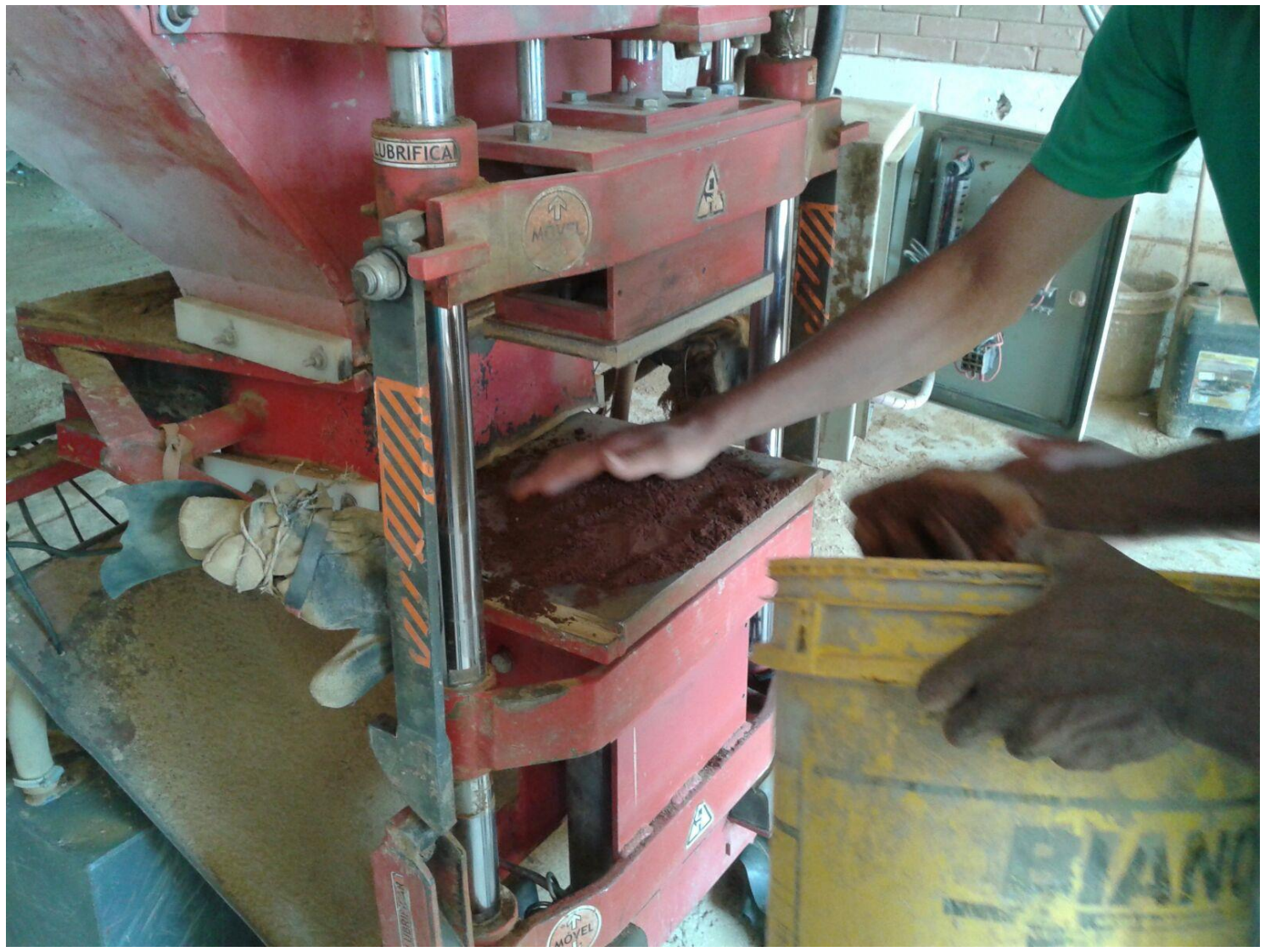

Fonte: Autoria própria, 2015. 
Figura 5 - Estocagem dos corpos de prova

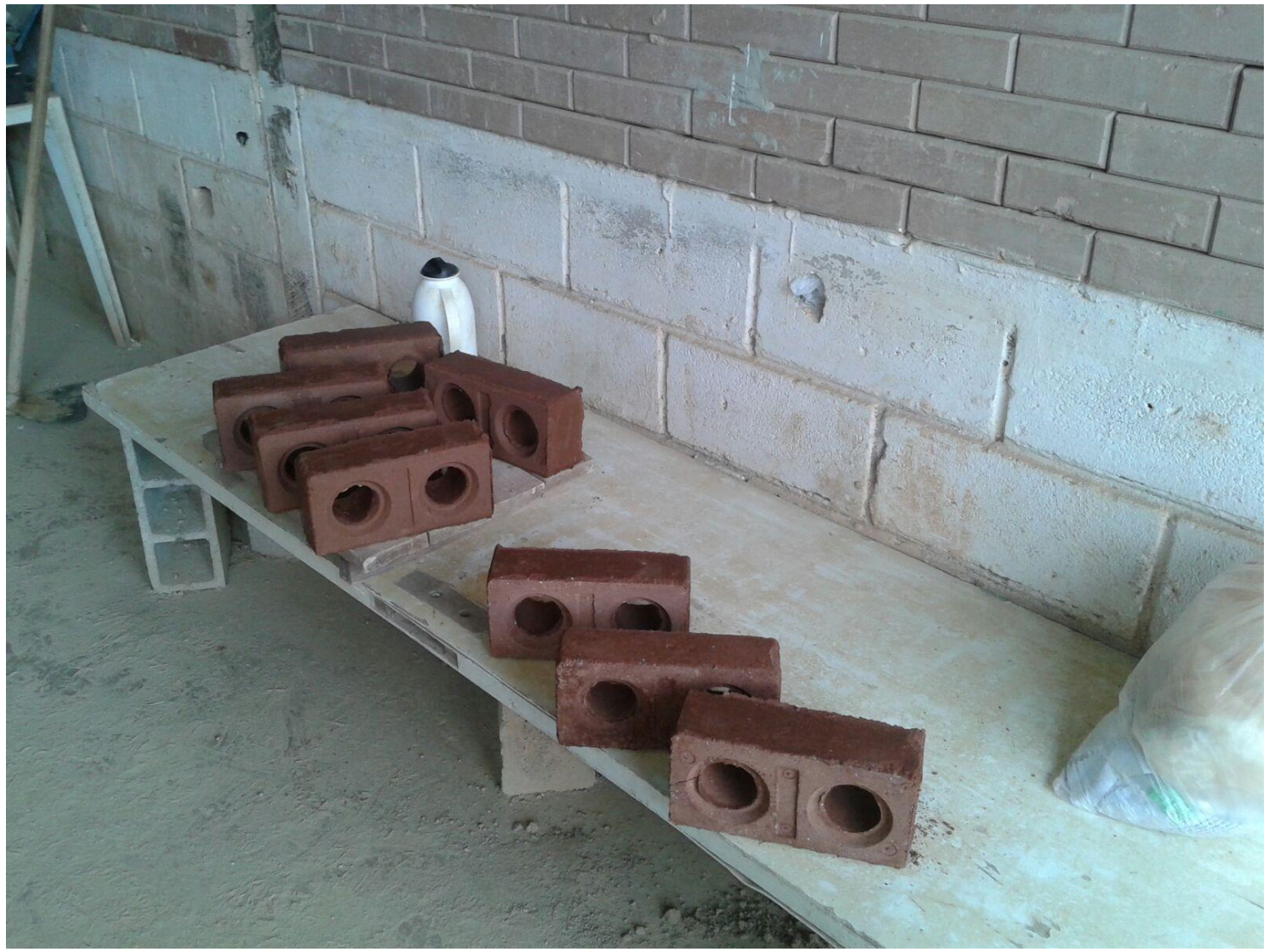

Fonte: Autoria própria, 2015.

Depois da prensagem, os tijolos foram estocados por um período de quatro dias e hidratados por um borrifador (Figura 5) pelos trabalhadores da fábrica Ecobauer, seguindo todo o processo de cura de um tijolo. Para tornar o processo mais sustentável, os tijolos foram secos ao sol. 


\subsection{Resistência dos corpos de prova}

Os ensaios de resistência dos corpos de prova foram realizados seguindo a norma NBR 8492 de compressão dos tijolos. Foi feito o ensaio na prensa hidráulica da marca Amsler (Figura 6) no laboratório de campo de Engenharia Civil da PUC Minas.

\section{Figura 6 - Prensa Hidráulica}

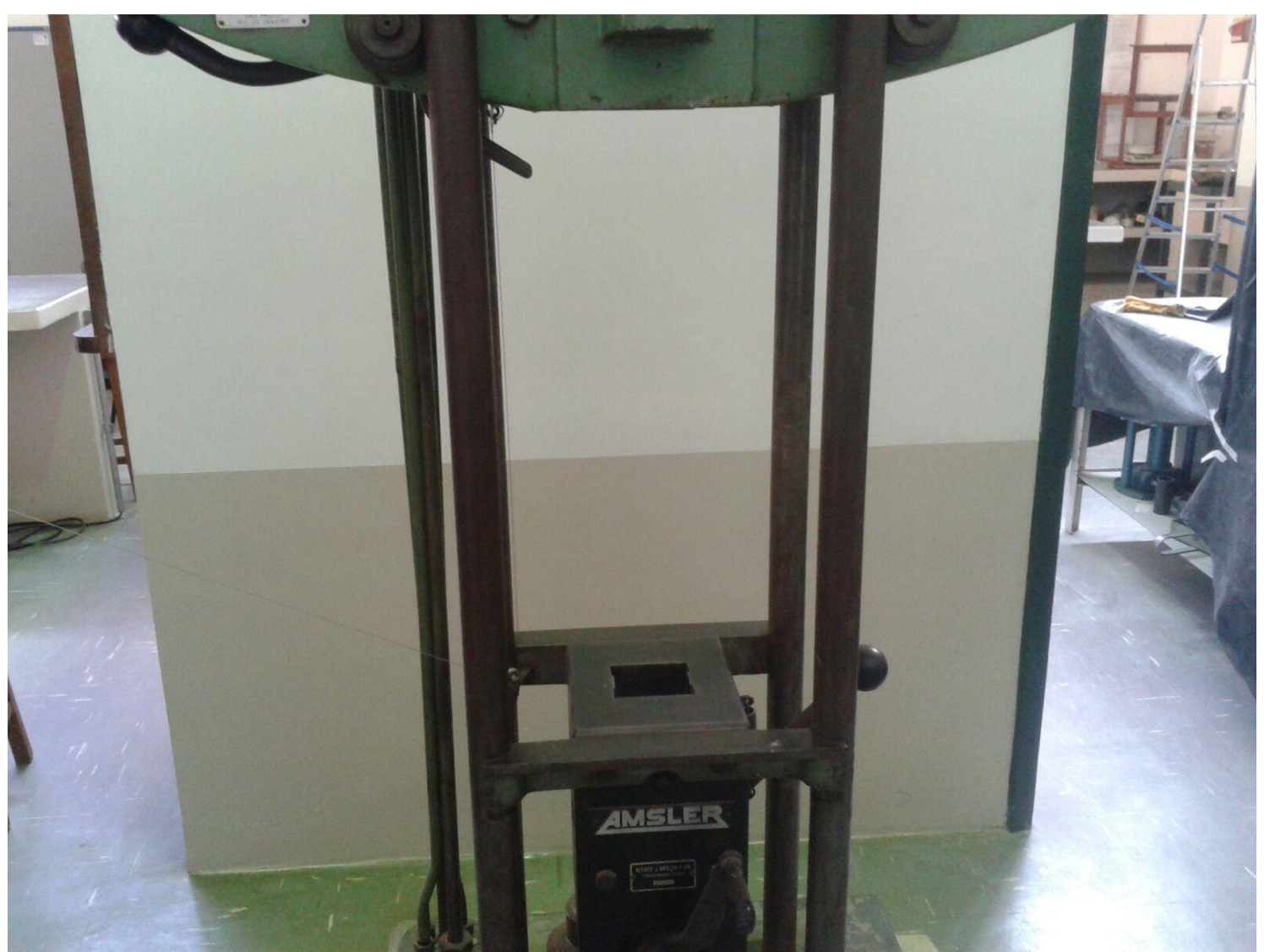

Fonte: Autoria própria, 2015. 


\section{Resultados e discussões}

A Figura7 mostra os resultados obtidos nos testes de compressão aos 7 e 14 dias, especificados de acordo com a norma NBR 8492, realizados no laboratório de Engenharia Civil da PUC Minas, no Coração Eucarístico:

\section{Figura 7 - Teste de Compressão}

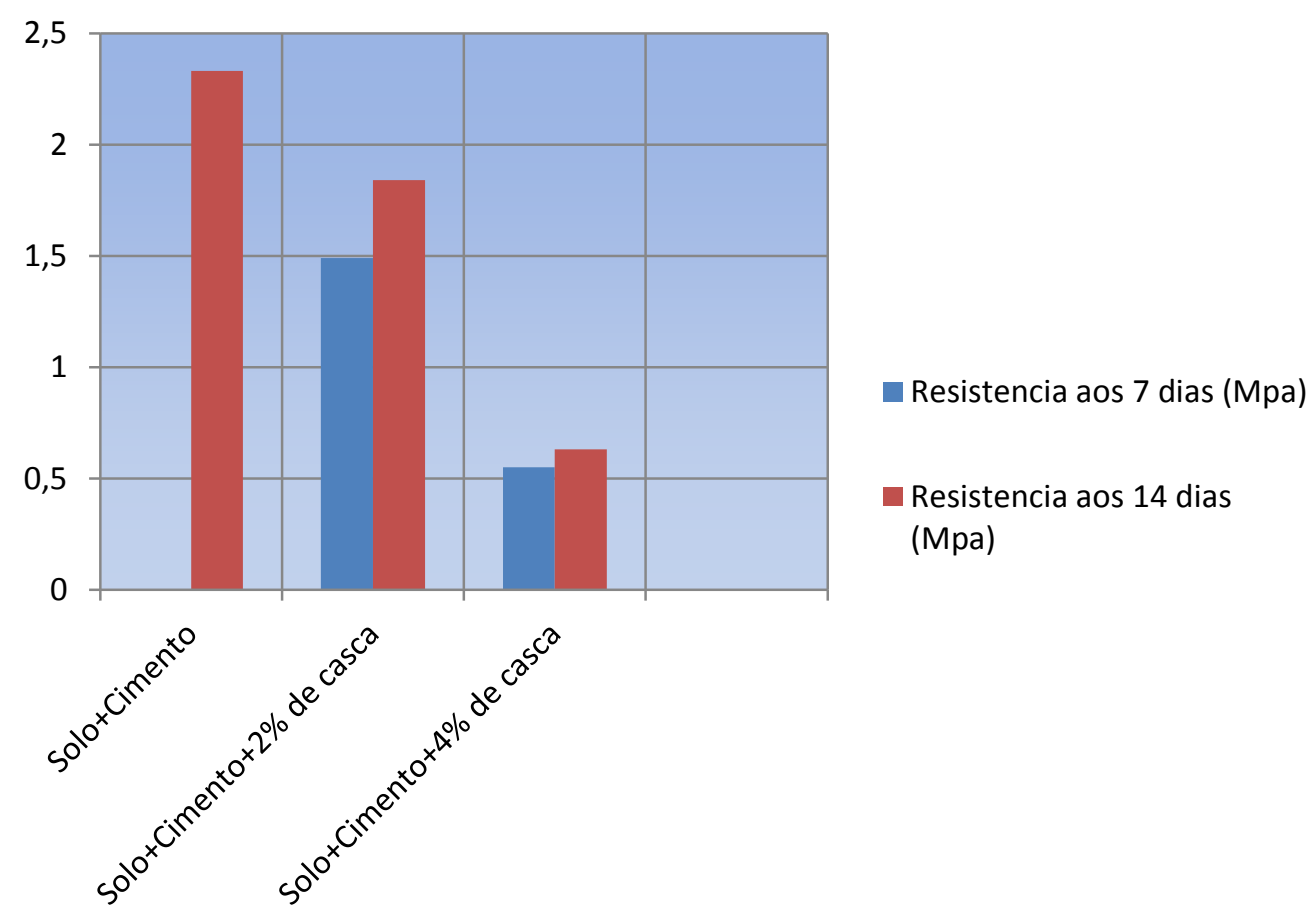

Fonte: Autoria própria, 2015.

Observou-se que, diminuindo a quantidade de cimento e aumentando a quantidade de casca de banana, o tijolo foi perdendo resistência.

Foi detectado que, logo após a prensagem dos tijolos, aqueles que possuíam a casca de banana apresentavam muito mais liga que aqueles sem a casca de banana. Entretanto, apesar dessa liga, os tijolos mostravam-se expandidos, evidenciando assim, que a casca de banana tem a característica de absorção de água. Com essa característica, os tijolos são expandidos, ocasionando fissuras, diminuindo assim a sua resistência. Mesmo depois do período de cura, notava-se claramente que os tijolos provenientes de casca de banana estavam mais "umedecidos" que aqueles sem banana, comprovando que houve a absorção de água por parte das cascas. 
Diferentemente da absorção prevista pela NBR 8491, segundo a qual os tijolos, após secos em estufas, são umedecidos por um borrifador (relatando assim a porcentagem de sua absorção), os tijolos provenientes de cascas de bananas absorvem água logo no período de cura. Isso é observado devido à sua expansão após o fim da prensagem (Figura 8), não necessitando assim do teste de absorção após o fim do tempo de cura.

Comparando-se os tijolos com a adição do pó da casca de banana e os sem adição, pode-se observar que, ao terceiro dia do período de cura, o tijolo sem a incorporação da casca de banana manteve-se intacto, enquanto o tijolo incorporado de casca de banana tornou-se expandido (Figura 9).

\section{Figura 8 - Tijolo expandido após a prensagem}

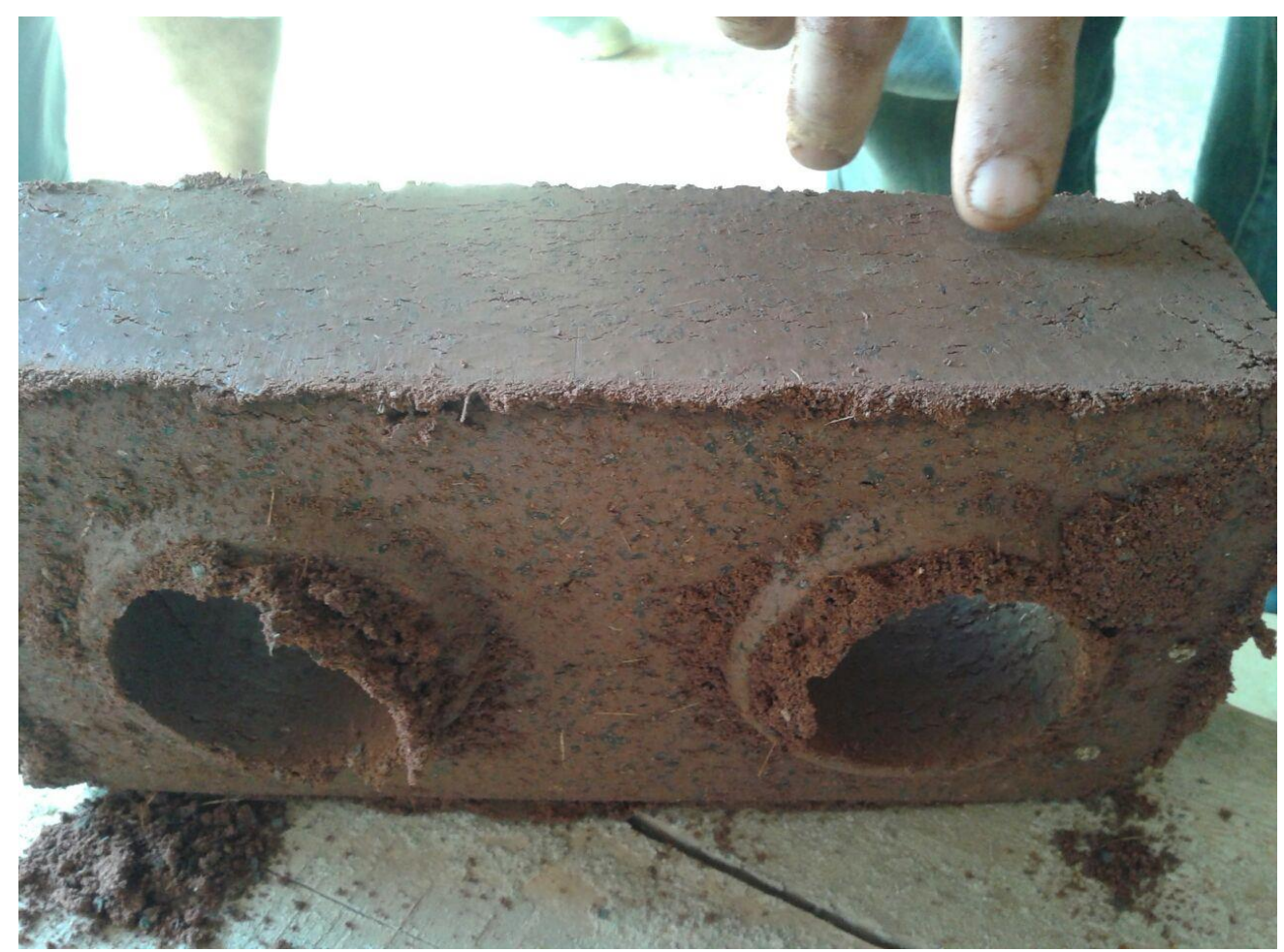

Fonte: Autoria própria, 2015. 


\section{Figura 9 - Comparação ao terceiro dia de cura}

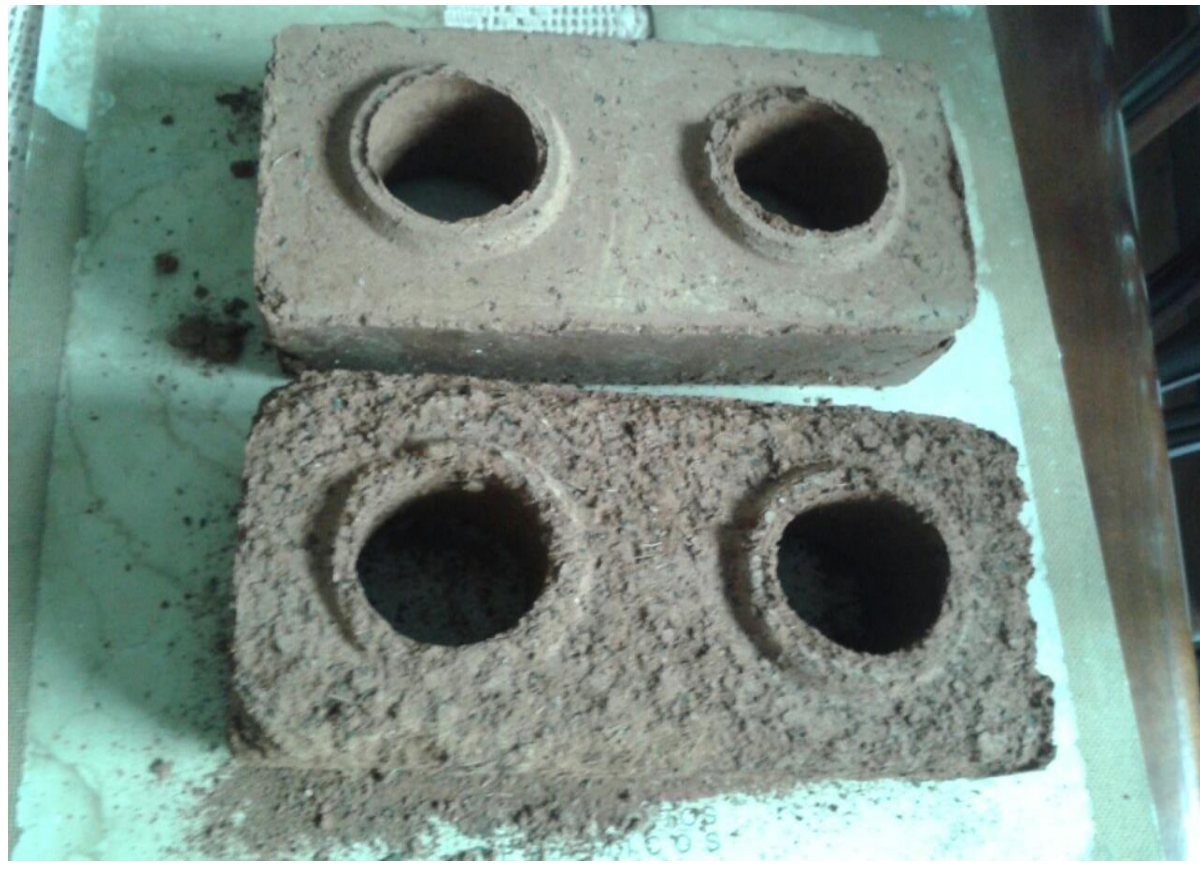

Fonte: Autoria própria, 2015.

Com isso, observa-se que a sílica contida na casca da banana pode exercer a função ligante do cimento, comprovando o que foi dito por Opefergelt (2006), segundo o qual a biomineralização de sílica em bananas fraciona os isótopos de silício estáveis na mesma medida em ambiente natural e em hidropônica.

Porém, devido a essa característica exacerbada de absorção de água, torna-se inviável a sua utilização em obras de grande porte, como casas, galpões etc., por não atender às condições mínimas de resistência de 2MPA prevista pela norma NBR 8491. Entretanto, em obras de pequeno porte, que não necessitam de uma grande resistência, especificado pela norma NBR 10834 (que versa sobre os blocos de solo-cimento sem função estrutural), o tijolo de casca de banana se torna até mais atrativo pela sua coloração em tons de marrom e pelo aroma da própria banana mantido no tijolo.

\section{Conclusão}


Diante dos resultados experimentais, constata-se que os tijolos de solo-cimento sem a incorporação da casca de banana se mostraram viáveis por atender aos requisitos mínimos de resistência exigidos pelas normas técnicas. Já os tijolos com casca de banana mostraram-se inviáveis, por não atenderem às condições mínimas de resistência. Entretanto, em pequenas obras como: fogão a lenha, base para mesa, decoração, entre outras funcionalidades (obras que não necessitam de uma grande resistência), o tijolo oriundo do bagaço da casca de banana torna-se viável ecológica e economicamente, uma vez que não necessita de sua queima e mão-de-obra qualificada em relação aos tijolos convencionais.

Salienta-se que a presente pesquisa buscou encontrar um caminho mais viável para a construção civil e diminuir impactos sobre o meio ambiente, por isso tal pesquisa não seria possível sem a ajuda do programa de bolsa de iniciação cientifica do PROBIC/FAPEMIG. 
BERNADE, Bruna Magnago. Estudo da cinética de extração alcoólica durante o processamento de licor de banana. 2014. 87f. Dissertação (Mestrado) - Universidade Federal do Espírito Santo, programa de pós-graduação em ciência e tecnologia de alimentos, UFES, Alegre.

COELHO, R. R. Pessoa MATA, M. E. R. M. Cavalcanti; BRAGA, M. E. Duarte. Alterações dos componentes nutricionais do pseudocaule da bananeira quando processado visando sua transformação em palmito. Revista Brasileira de produtos agroindustriais, Campina Grande, v.3, n.1, p.21-30, 2001.

CORREA, L. R; Sustentabilidade na construção civil. Belo Horizonte: Universidade Federal de Minas Gerais, 2009.

CORREA, J.C; FERREIRA, F. Fernandes; GUIMARÃES, R. C. Melo. Tijolo ecológico de bagaço de cana-de-açúcar. In: SIMPÓSIO DE TECNOLOGIA SUCROENERGÉTICA E DE BIOCOMBUSTÍVEIS, 5, 2013, Jaboticabal. Anais... Jaboticabal, 2013.

KANNING, R. César. Utilização da cinza de folha de bananeira como adição em argamassas de cimento portland. 2013.192f. Tese (Doutorado) - Universidade Federal do Paraná, programa de pós-graduação em Engenharia-PIPE, UFPA, Curitiba.

OPEFERGELT, S; CARDINAL, D; HENRIET, C; ANDRÉ, L; DELVAUX, B. Silicon isotope fractionation between plant parts in banana: In situ vs in vintro. Journal of Geochemical Exploration, Leuvensesteenweg, Bélgica, v.88, p.224-227, 2006.

RIBEIRO FILHO, J. N.; SILVA, G. N; LUCENA, K. F. M; CARVALHO, N. H. C. Projeto e execução de casa ecoeficiente em Campina Grande - PB. Coordenação de ciências gerenciais, CEFET-PB, João Pessoa, 2006. 